\title{
A EMPREGABILIDADE DOS GRADUADOS Competências procuradas nos anúncios de emprego
}

\author{
Ana Costa Laranjeiro \\ Instituto Universitário de Lisboa (ISCTE-IUL), Lisboa, Portugal
}

Fátima Suleman

Instituto Universitário de Lisboa (ISCTE-IUL), Dinâmia'Cet_Iscte, Lisboa, Portugal

Maria do Carmo Botelho

Instituto Universitário de Lisboa (ISCTE-IUL), Centro de Investigação e Estudos de Sociologia (Cies_Iscte), Lisboa, Portugal

Resumo Esta pesquisa visa identificar competências requeridas no recrutamento de graduados através da análise de anúncios de emprego $(\mathrm{n}=813)$. A língua estrangeira, em especial o inglês, é uma competência amplamente requerida e pode ser considerada uma competência-chave. Outros requisitos apontam para conhecimentos técnicos, competências relacionais e organizacionais, e certos traços pessoais. Todavia, essas exigências variam em função da área de formação. Há igualmente anúncios que indicam apenas a área de formação sem especificar competências. Esses sugerem a procura de competências técnicas associadas à licenciatura.

Palavras-chave: ensino superior, requisitos do emprego, competências, anúncios de oferta de emprego.

The employability of graduates: skills sought in job advertisements

Abstract This research examines job advertisements $(n=813)$ to identify the skills required to graduates in the hiring process. Foreign language, notably English, is highly demanded; it may be labeled as key skill. Other requirements point to technical knowledge, relational and organizational skills, and some personal traits. However, job requirements vary across field of education. Some advertisements report only the field of education without detailing skills. These job offers suggest the demand for technical skills specific to the graduation.

Keywords: higher education, job requirements, skills, job advertisements.

L'employabilité des diplômés: compétences recherchées dans les offres d'emploi

Résumé Cette recherche vise à identifier les compétences requises pour le recrutement de diplômés par l'analyse des offres d'emploi $(n=813)$. La langue étrangère, en particulier l'anglais, est une compétence largement requise et peut être considérée comme une compétence clé. D’autres exigences portent sur les connaissances techniques, les compétences relationnelles et organisationnelles et certains traits personnels. Toutefois, ces exigences varient en fonction du domaine de formation. Il existe également des annonces indiquant uniquement le domaine de formation sans préciser les compétences. Celles-ci suggèrent la demande de compétences techniques associées à un diplôme.

Mots clés: enseignement supérieur, exigences d'emploi, compétences, offres d'emploi.

La empleabilidad de los graduados: habilidades buscadas en los anuncios de trabajo

Resumen Esta investigación tiene como objetivo identificar las habilidades requeridas en el reclutamiento de graduados a través del análisis de los anuncios de trabajo $(n=813)$. El idioma extranjero, en particular el inglés, es una competencia ampliamente requerida y puede considerarse una competencia clave. Otros requisitos apuntan a conocimientos técnicos, habilidades relacionales y organizativas, y ciertos rasgos personales. Sin embargo, estos requisitos varían según el área de formación. También hay anuncios que indican sólo el área de formación sin especificar las competencias. Esto sugiere la demanda de habilidades técnicas asociadas con un título académico.

Palabras-clave: educación superior, requisitos del empleo, competencias, anuncios de empleo. 


\section{Introdução}

O desemprego de diplomados e o desajustamento de qualificações têm contribuído para intensificar o debate sobre a relação entre a educação e o emprego nos últimos anos (Cardoso et al., 2012; Figueiredo, Teixeira e Rubery, 2013; Mavromaras et al., 2013; Gonçalves, 2017). As instituições do ensino superior estão fortemente pressionadas a transmitir ou desenvolver competências ajustadas às necessidades da economia e do mercado de trabalho e, deste modo, aumentar a empregabilidade dos graduados. O pressuposto central é que os empregadores transformam empregabilidade em emprego (Harvey, 2001). Por isso, os jovens devem adquirir competências que respondam às necessidades dos empregadores. Esta pesquisa contribui para essa discussão e utiliza os anúncios de emprego como fonte privilegiada de informação para identificar as competências exigidas aos licenciados e mestres em Portugal.

Este método da análise de empregos através de anúncios de emprego tem sido adotado em vários estudos internacionais (e.g. Bennett, 2002; Pitt e Mewburn, 2016), e nacionais (e.g. Almeida, 2000; Torres, 2008) e permite um acesso à informação sem custos adicionais e sem uma inquirição direta. Gorter, Nijkamp e Rietveld (1996) sugerem que os empregadores utilizam os anúncios de emprego como uma primeira estratégia de recrutamento, através da qual procuram criar uma base de candidatos. Todavia, os estudos disponíveis incidem sobre uma área ou subárea específica de formação (e.g. Bennett, 2002; Almeida, 2000) ou a uma função (e.g. Torres, 2008). Este trabalho pretende ser, por um lado, mais abrangente e, por isso, inclui todas as ofertas de emprego para graduados. Por outro lado, incide sobre ofertas para jovens graduados, com idade até 35 anos ou experiência profissional até três anos. Julgamos que estas condições não têm sido definidas nos estudos disponíveis. A nossa pesquisa permite, por isso, comparar as competências pretendidas nos jovens graduados, para diferentes funções, as quais pressupõem uma diversidade de áreas de formação.

As questões de pesquisa que enformam este trabalho são obviamente relativas à incidência de determinados tipos de competências, mas igualmente sobre as áreas de formação em que existe mais oferta de emprego. Pretendemos verificar: (1) Quais as competências procuradas no mercado de trabalho português? (2) Existe alguma relação entre áreas de formação e especificação de competências nos anúncios de emprego? (3) Em que medida as áreas técnicas (e.g. engenharia, saúde) e as ciências sociais diferem no tipo de competências procuradas?

A análise empírica incide sobre anúncios de emprego $(\mathrm{n}=813)$ recolhidos em Portugal, entre janeiro e outubro de 2015. Os anúncios especificam uma diversidade de competências com denominações distintas. Por isso, a análise empírica visa, num primeiro momento, agregar as competências, a partir de uma análise de conteúdo, com vista a obter um número mais reduzido e operacional. Num segundo momento, aplica-se uma análise de correspondências múltiplas e análise de clusters, hierárquica e não hierárquica, para identificar tipos de competências mais procuradas no mercado de trabalho português.

O resto do trabalho está organizado da seguinte forma: a secção seguinte apresenta os contributos teóricos relativos às competências que visam aumentar a 
empregabilidade dos graduados; a terceira secção incide sobre a metodologia relativa à recolha e tratamento dos dados; a secção 4 oferece os resultados empíricos relativos aos tipos de competências procuradas e outros atributos associados a esses tipos; finalmente, a última secção expõe algumas notas conclusivas.

\section{Graduados e mercado de trabalho}

As competências para empregabilidade: uma classificação difícil

Sob a designação de "competências para empregabilidade" (employability skills), uma vasta literatura incide no debate da relação entre formação e emprego, procurando identificar os tipos de competências procuradas no mercado de trabalho (veja-se Suleman, 2017, para uma revisão da literatura). A discussão dos conceitos de competência ${ }^{1}$ e de empregabilidade ${ }^{2}$ ultrapassa o âmbito deste trabalho. Todavia, é importante recordar que a investigação reconhece que um indivíduo representa um vetor de atributos, o qual inclui, entre outros, a educação e as competências que são relevantes para a sua empregabilidade (Suleman e Suleman, 2012), ou seja, para entrar e manter-se no mercado de trabalho (Hillage e Pollard, 1998).

Neste sentido, os autores sublinham que a empregabilidade diz respeito à propensão dos indivíduos para mostrarem as capacidades exigidas pelos empregadores. Por isso, a auscultação dos empregadores sobre os requisitos exigidos aos candidatos ao emprego, em particular aos diplomados do ensino superior, é crucial para garantir uma transição mais fácil entre o sistema universitário e o mercado de trabalho. A revisão de literatura incide assim na análise das competências que aumentam a probabilidade de um graduado aceder e manter-se no mercado de trabalho.

A investigação sobre as competências para a empregabilidade retoma em parte o caminho proposto por Becker (1964), na medida em que visa identificar o conjunto de competências específicas e/ou gerais que o mercado de trabalho exige aos graduados. A literatura oferece diversas indicações sobre essas competências. Por exemplo, Bennett (2002) sistematiza as capacidades que surgem numa vasta literatura académica e governamental e enumera nove competências: adaptabilidade / flexibilidade, capacidades analíticas, de comunicação, de iniciativa, de utilização de meios informáticos, de liderança, de organização, motivação, e numeracia. A proposta de Washer (2007) inclui sete competências e é parcialmente próxima da proposta de Bennett. $\mathrm{O}$ autor acrescenta a resolução de problemas, aprender a aprender e desenvolvimento pessoal e profissional. Por seu lado, Tymon (2013) sublinha que existe um consenso alargado apenas relativamente a três capacidades que são

1 Para a definição e discussão do conceito de competência sugere-se Vazirani (2010) ou Velden (2013).

2 Do mesmo modo, não se pretende uma discussão do conceito de empregabilidade neste artigo. A literatura disponível aponta para a preparação para o mercado de trabalho, mas sublinhando a interação entre as dimensões individual e contextual (McQuaid e Lindsay, 2005). Veja-se outras referências relevantes em Suleman (2017). 
Quadro 1 Classificação das competências: exemplos a partir de estudos empíricos

\begin{tabular}{|c|c|c|c|c|}
\hline Competências & $\begin{array}{l}\text { Suleman } \\
(2012)\end{array}$ & $\begin{array}{l}\text { Olivier et al. } \\
(2014)\end{array}$ & $\begin{array}{l}\text { Teijeiro, Rungo } \\
\text { e Freire (2013) }\end{array}$ & $\begin{array}{l}\text { García-Aracil } \\
\text { e Velden (2008) }\end{array}$ \\
\hline Conhecimentos técnicos gerais & $\begin{array}{l}\text { Conhecimentos } \\
\text { gerais }\end{array}$ & & & \\
\hline Conhecimentos técnicos específicos & Cognitivas & $\begin{array}{l}\text { Técnicas e } \\
\text { específicas }\end{array}$ & Instrumentais & Especializadas \\
\hline Conhecimento de línguas & $\begin{array}{l}\text { Conhecimentos } \\
\text { gerais }\end{array}$ & & & \\
\hline Colegas & Relacionais & & & \\
\hline Equipa & Relacionais & $\begin{array}{l}\text { Equipa e } \\
\text { interpessoais }\end{array}$ & Interpessoais & \\
\hline Comunicação & Relacionais & Basilares & Instrumentais & Gerais \\
\hline Ajuda & Relacionais & & & \\
\hline Negociação & Estratégicas & & & \\
\hline Persuasão & Estratégicas & & & \\
\hline Perseverança e orientação resultados & Estratégicas & & Sistémicas & \\
\hline Orientação para o cliente & Estratégicas & & & \\
\hline Autonomia & Cognitivas & & Sistémicas & Organizacionais \\
\hline Responsabilidade & Cognitivas & & Sistémicas & Participativas \\
\hline Capacidade de adaptação & Cognitivas & Adaptabilidade & & \\
\hline Inovação & Cognitivas & Adaptabilidade & Sistémicas & \\
\hline Disponibilidade para aprender & Organizacionais & & & \\
\hline Esforço de aprendizagem & Organizacionais & Adaptabilidade & & \\
\hline Cumprir regras e procedimentos & Organizacionais & & & \\
\hline Cooperação & Estratégicas & & & \\
\hline Adaptação do horário de trabalho & Organizacionais & & & \\
\hline Pontualidade & Organizacionais & & & \\
\hline Planear e organizar o trabalho & Cognitivas & & Instrumentais & Participativas \\
\hline Utilizar sistemas informáticos & Cognitivas & Informática & & \\
\hline Capacidade de análise & Cognitivas & Basilares & Instrumentais & Gerais \\
\hline Selecionar e processar informação & Cognitivas & & & \\
\hline Capacidade de resolução de problemas & Cognitivas & Basilares & Instrumentais & Metodológicas \\
\hline Capacidade para aprender & Cognitivas & & & \\
\hline Transferir e transpor conhecimentos & Cognitivas & & & \\
\hline Compreender especificidade & Cognitivas & & & \\
\hline Compreender estratégia do banco & Estratégicas & & & \\
\hline Trabalhar sob pressão e stress & & Empregabilidade & & Organizacionais \\
\hline Cumprir prazos & & Empregabilidade & & \\
\hline Atenção ao detalhe & & & & Organizacionais \\
\hline Tomar decisões & & & Instrumentais & Participativas \\
\hline Motivação para o trabalho & & & Sistémicas & \\
\hline Preocupação com a qualidade & & & Sistémicas & \\
\hline
\end{tabular}


consideradas importantes para o empregador: capacidades de comunicação, interpessoais e de trabalho em equipa. Suleman (2017) encontra um consenso igualmente reduzido na literatura em torno de seis competências: comunicação, trabalho em equipa, pensamento analítico e crítico, capacidade para aprender, informática, capacidade para planear e organizar.

Alguma literatura oferece uma classificação das competências procuradas. Andrews e Higson (2008) sublinham que os empregadores procuram capacidades técnicas e não técnicas, ou seja, hard e soft skills. Branine (2008) salienta a procura de competências pessoais (person-related), tais como atitude, personalidade e competências transferíveis, mais do que competências relacionadas com os requisitos do emprego (job-related). Outros autores sugerem uma diversidade de tipos de competências, bem como múltiplas designações para uma mesma competência (ver quadro 1). ${ }^{3}$

Sublinhe-se, a título de exemplo, a capacidade de comunicação. Para Suleman (2012) trata-se, pela sua natureza, de uma competência relacional, para Olivier et al. (2014) trata-se de uma competência basilar, e Teijeiro, Rungo e Freire (2013) reconhecem-na como instrumental. Finalmente, Garcia-Aracil e Velden (2008) classificam a capacidade de comunicação como competência geral que será útil em todos os contextos de trabalho.

Esta diversidade de classificações parece ser habitual em ciências sociais, especialmente quando é construída a partir dos dados e da aplicação de métodos estatísticos multivariados. A pertença de competências a um grupo homogéneo levanta todavia dúvidas sobre a sua coerência interna. Por exemplo, a capacidade de trabalhar com sistemas informáticos não parece ser uma competência cognitiva (Suleman, 2012), contudo a proposta de Olivier et al. (2014) também parece redundante. A classificação dos conhecimentos técnicos parece mais clara nas propostas de outros autores do que na de Suleman (2012). De facto, esses conhecimentos tendem a ser técnicos e específicos (Olivier et al., 2014) e especializados (Garcia-Aracil e van der Velden, 2008). São igualmente instrumentais, na medida em que apoiam a atividade profissional de forma clara (Teijeiro, Rungo e Freire, 2013).

Além disso, as classificações apresentadas focam superficialmente os traços pessoais. Apenas Teijeiro, Rungo e Freire indicam a motivação para o trabalho como uma capacidade sistémica. Finalmente, este esforço suscita ainda uma questão relativa à compreensão dos termos por parte dos empregadores e outros atores interessados no ensino superior (Billing, 2003).

Bennett (2002) acrescenta ainda que as competências procuradas variam em função dos empregos. Importa referir a este propósito que as competências dos gestores têm sido trabalhadas desde longa data (e.g. Boyatzis, 1982; Morand, 2001; Ellis, 2003). Os investigadores procuram insistentemente identificar as competências que aumentam a performance, a qual pressupõe uma diversidade de capacidades. Por exemplo, Morand (2001) sublinha capacidades interpessoais (people skills) e enfatiza a inteligência emocional; Ellis (2003) descreve a importância da capacidade de comunicação. Por

3 A análise da literatura que oferece classificação de competências parte do contributo de Suleman (2012), na medida em que este inclui uma ampla lista de competências. O exercício seguinte é, assim, identificar outras classificações para uma mesma competência. 
seu lado, Bennett (2002) encontrou diferenças significativas nos empregos ligados à área de gestão, designadamente marketing, gestão geral, finanças e gestão dos recursos humanos. Por exemplo, a capacidade de trabalhar com números é mais relevante para a área financeira, enquanto as outras exigem a capacidade de comunicação. Estudos mais recentes indicam que os gestores necessitam de qualidades pessoais, como entusiasmo, dedicação e disponibilidade para trabalhar muito, e capacidades interpessoais, designadamente trabalhar em equipa (Velasco, 2012).

Outros estudos, que procuram determinar as competências por profissão, indicam que a capacidade de comunicação é relevante para os engenheiros (Sageev e Romanowski, 2001; Riemer, 2007). Todavia, Sageev e Romanowski criticam a insuficiente preparação dos graduados nesta competência. Para Riemer, a comunicação é multifacetada e inclui a escrita e a oralidade, mas igualmente a escuta, a imagem visual, a interdisciplinaridade e a interculturalidade. A comunicação surge também como uma capacidade crucial nas profissões da saúde. Maguire e Pitceathly (2002) sublinham o benefício de uma boa comunicação entre o médico e o paciente, como forma eficaz de diagnóstico. Kennan et al. (2009) sublinham a relevância de características pessoais e capacidades de comunicação, a par de conhecimentos técnicos para áreas de tecnologias de informação. Os exemplos apresentados apontam para a existência de competências transversais a várias profissões. Indicam ainda que essas competências comuns carecem de especificação em função dos contextos profissionais particulares.

A análise dos estudos sobre competências indica que os empregadores procuram graduados com determinados atributos, os quais não se limitam ao nível de escolaridade. Todavia, a diversidade de competências para a empregabilidade que a literatura detalha não facilita o trabalho nem dos candidatos nem do ensino superior, que devem ter uma informação mais ampla e consensual.

Identificação das competências para a empregabilidade: os anúncios de emprego

Os empregadores podem iniciar um processo de recrutamento a partir de anúncios de emprego, os quais permitem criar uma base de recrutamento de futuros empregados (Gorter, Nijkamp e Rietveld, 1996). Com a enumeração das competências requeridas, os empregadores procuram: atrair candidatos ajustados ao emprego; transmitir padrões de atributos e os requisitos habitualmente exigidos pela empresa; e selecionar candidatos com base nas competências. Esta última razão significa que as empresas não limitam os seus critérios de seleção à formação académica, acreditando que o sistema educativo tenha transmitido as capacidades produtivas necessárias, como preconizado pela teoria do filtro (Arrow, 1973). Muito pelo contrário, desconfiam desse papel e apontam críticas ao sistema de ensino relativamente à insuficiente preparação dos graduados (Hesketh, 2000; Bennett, 2002; Kavanagh e Drennan, 2008).

De facto, a análise dos anúncios de emprego tem vindo a ser uma ferramenta importante na identificação das competências procuradas (Almeida, 2000; Bennett, 2002; Torres, 2008; Kennan et al., 2009; Pitt e Mewburn, 2016). Trata-se de documentos públicos que disponibilizam informação sobre requisitos de emprego que os 
empregadores consideram essenciais (Messum, Wilkes e Jackson, 2011). Lanier (2009) refere, por um lado, que os anúncios de emprego nos sítios da internet têm sido amplamente usados pelas 500 maiores empresas dos Estados Unidos e, por outro, reporta uma redução substancial de custos $(20 \%)$ em relação a formas tradicionais de recrutamento. A investigação disponível baseada nos anúncios é contudo dispersa, incidindo sobre uma ou mais profissões ou formações.

Ao nível internacional, Bennett (2002) analisou 1000 anúncios publicados em sítios da internet, de emprego direcionado para recém-licenciados e vagas publicadas numa universidade no Reino Unido durante alguns períodos entre 2000 e 2001. O seu estudo visou a identificação das necessidades de competências relacionadas com as categorias de trabalho e o nível de salário, nas áreas de marketing, finanças, gestão e recursos humanos. Outro estudo mais recente, realizado por Pitt e Mewburn (2016), analisou 178 anúncios de emprego para funções que especificam o doutoramento como critério de seleção, publicados num só dia, em oito universidades australianas. Já a nível nacional, Almeida (2000) baseou-se na recolha de anúncios num semanário, num período de dois anos, para análise das competências requeridas a profissionais de recursos humanos para quatro categorias de funções: diretores, chefes de serviços, técnicos e consultores. Na mesma linha, Torres (2008) analisou 639 anúncios do mesmo semanário, entre 2006 e 2008, para identificar padrões da oferta de emprego também na área de gestão de recursos humanos em Portugal. A sua análise inclui igualmente as áreas de formação transversais que permitem aceder às funções associadas à gestão de recursos humanos, nomeadamente, sociologia, psicologia, recursos humanos, gestão, direito, economia e educação.

Como se pode notar, certos estudos procuram analisar as competências requeridas na área de gestão e especialidades dentro da gestão (Bennett, 2002; Arcodia e Barker, 2002). Outros trabalhos centram-se em profissões como as da saúde (Messum, Wilkes e Jackson, 2011). Outros ainda ocupam-se das competências relacionadas com as atividades que se transformaram devido à evolução tecnológica. Choi e Rasmussen (2009) descrevem as competências requeridas na função de bibliotecário digital, enquanto Henricks e Henricks-Lepp (2014) especificam competências para diretor de bibliotecas públicas. Há ainda o estudo de Lanier (2009), que se concentra numa competência-chave, que é a comunicação técnica. Sem qualquer pretensão de sermos exaustivos, podemos aferir desta literatura que os anúncios de emprego têm de facto constituído uma fonte relevante na identificação de competências requeridas pelos empregadores.

Este trabalho inspira-se nessa literatura e procura aferir em que medida o mercado de trabalho português segue o padrão internacional relativamente às competências requeridas aos graduados. Apesar da sua relevância, os estudos disponíveis, especialmente no caso português, são limitados a uma profissão (Almeida, 2000; Torres, 2008). No contexto de expansão do ensino superior em Portugal, parece-nos relevante alargar a análise ao ensino superior e identificar os tipos de competências exigidos aos graduados de diferentes áreas de formação e/ou para diferentes funções.

Tendo em atenção a revisão da literatura, sugerimos as seguintes hipóteses de pesquisa: 
- H1: os empregadores enumeram as competências gerais nos anúncios enquanto as competências específicas estão implícitas na área de formação.

- H2: os empregadores procuram atrair candidatos com certos traços pessoais.

- H3: as competências requeridas variam em função da profissão e da área de formação para as quais há ofertas de emprego.

\section{Dados e metodologia}

\section{Conteúdos dos anúncios de emprego}

Os dados utilizados nesta pesquisa provêm de 813 anúncios de emprego, divulgados em sítios da internet em Portugal. A informação foi recolhida entre janeiro e outubro de 2015, para todos os anúncios que visam ofertas de emprego para licenciados e mestres ${ }^{4} \mathrm{em}$ território nacional, em sítios específicos da internet, ${ }^{5}$ tendo em conta os seguintes critérios:

- Os anúncios devem ter uma única referência. Assim sendo, a seleção tem em conta o número de referência, o que permite evitar a recolha de anúncios repetidos que surgem em dias diferentes.

- Os anúncios devem indicar formação superior (mínimo licenciatura) como requisito mínimo. Recorde-se que certas ofertas de emprego dirigidas às mesmas designações de função, exigem graus académicos diferentes. ${ }^{6}$

- As ofertas de emprego devem ser essencialmente dirigidas a jovens recém-graduados (incidido preferencialmente na experiência até três anos ou idade até 35 anos). Importa referir que um grande número de anúncios omite a referência ao intervalo de idades. Nesses casos, a seleção de anúncios recorre a outra informação disponível, designadamente a referência à carreira (e.g. consultor júnior); ao tempo de graduação (e.g. recém-licenciado) ou ao tempo de experiência (e.g. experiência de dois anos em funções similares).

O quadro 2 sistematiza a informação da base de dados construída e ilustra a diversidade de informação contida nos anúncios selecionados para este estudo. Como se pode verificar, a informação sobre os empregos oferecidos não é uniforme. A totalidade dos anúncios informa sobre a área de formação e a região do local de trabalho. A informação sobre o setor de atividade é também indicada num considerável número de

4 Os anúncios fazem referência a licenciatura, mestrado, ou formação/curso superior.

5 Os sítios consultados são: Net-Empregos: ofertas@net-empregos.com; rede social Linkedin, que encaminhava por vezes para páginas das empresas em que os anúncios eram divulgados; e ainda o jornal Expresso. Note-se que se excluíram da análise os anúncios repetidos nos diferentes sítios, bem como os que se repetiam por vários dias.

6 Por exemplo, diferentes anúncios indicam licenciatura e 12. ${ }^{\circ}$ ano para empregos como programador, técnico de contabilidade, ou técnico de vendas. 
Quadro 2 Informação contida nos anúncios $(n=813)$

\begin{tabular}{llr}
\hline Características & Informação & $\%$ \\
\hline Individuais & Área de formação & 100,0 \\
& Competências & 92,9 \\
& Idade & 4,7 \\
\hline Emprego & Valor do salário & 2,2 \\
& Composição da remuneração, mas sem referência ao valor do salário & 10,3 \\
& Outros benefícios & 1,1 \\
& Profissão & 99,8 \\
& Tipo de contrato & 72,8 \\
& Outras exigências & 48,9 \\
\hline & Nome da empresa & 64,2 \\
& Região & 100,0 \\
& Setor de atividade & 88,3 \\
\hline
\end{tabular}

Quadro 3 Ofertas de emprego por área de formação

\begin{tabular}{lcr}
\hline Área de formação & $\begin{array}{c}\text { Número de áreas } \\
\text { referenciadas }\end{array}$ & $\begin{array}{c}\text { Número } \\
\text { de anúncios }\end{array}$ \\
\hline Ciências & 10 & 20 \\
Tecnologias & 38 & 382 \\
Direito, ciências sociais e turismo & 28 & 82 \\
Economia, gestão e contabilidade & 15 & 209 \\
Educação física e desporto, ciências da educação & 5 & 5 \\
Saúde & 19 & 61 \\
Agricultura e recursos naturais & 7 & 22 \\
Humanidades, secretariado e tradução & 6 & 26 \\
Arquitetura, design e artes & 10 & 6 \\
Total & 138 & 813 \\
\hline
\end{tabular}

anúncios $(88,3 \%)$, bem como o tipo de contrato que se pretende oferecer aos potenciais candidatos $(72,8 \%)$. Há, todavia omissões que merecem uma atenção particular.

No que respeita às características dos candidatos, a idade é apenas indicada em $4,7 \%$ dos anúncios. Constata-se igualmente que as características do emprego estão praticamente ausentes, particularmente o valor do salário $(2,2 \%)$ e os benefícios $(1,1 \%)$ a oferecer pela empresa. Finalmente, apenas $64,2 \%$ de ofertas de emprego indicam o nome da empresa recrutadora. Em suma, certos anúncios de emprego são muito sumários, enquanto outros fornecem informação detalhada sobre os atributos procurados e as particularidades dos empregos e empregadores.

A procura de competências pode ser avaliada através das áreas de formação enunciadas e dos conhecimentos e capacidades listados nos anúncios de emprego. Existe uma diversidade de referências a áreas de formação (138 no total) que foram agrupadas a partir da classificação da Direção Geral do Ensino Superior (quadro3). Os resultados indicam que existe em Portugal uma importante oferta de emprego para as áreas tecnológicas, de economia e gestão. Em contrapartida, há pouca procura de 
Quadro 4 Tipos de competências enunciadas nos anúncios de emprego

\begin{tabular}{llc}
\hline Tipo de competência & Conhecimentos e capacidades & $\%$ \\
\hline Cognitivas, instrumentais, participativas & Planear e organizar & 52,0 \\
\hline Relacionais, basilares, instrumentais, gerais & Comunicação & 36,4 \\
\hline Relacionais, equipa e interpessoais & Trabalho em equipa & 36,4 \\
\hline Organizacionais, sistémicas & Atitudes face ao trabalho * & 32,8 \\
\hline Cognitivas, informática & Informática & 34,4 \\
\hline Cognitivas, sistémicas, participativas & Responsabilidade & 29,3 \\
& Dinamismo & 27,4 \\
\hline Equipa e interpessoais & Relacionamento interpessoal & 25,7 \\
& Proatividade & 24,2 \\
\hline Estratégicas & Orientação para os resultados, objetivos & 21,7 \\
\hline Cognitivas, basilares, instrumentais, gerais & Capacidade de análise & 20,9 \\
\hline Cognitivas, adaptabilidade & Adaptabilidade/flexibilidade & 13,8 \\
& Liderança & 13,7 \\
\hline Cognitivas, sistémicas, organizacionais & Autonomia & 13,3 \\
\hline Empregabilidade, organizacionais & Resiliência/resistência ao stress & 13,1 \\
& Iniciativa & 12,1 \\
\hline Estratégicas & Capacidades cognitivas & 11,7 \\
\hline Estratégicas & Espírito crítico & 8,7 \\
\hline & Negociação & 7,5 \\
\hline
\end{tabular}

* Exemplos de atitudes face ao trabalho incluem assiduidade, atenção ao detalhe, capacidade de trabalho, entre outras.

graduados em áreas de formação relacionadas com a agricultura, as humanidades, a educação física, e arquitetura e design.

Finalmente, as competências requeridas são enumeradas em 93\% dos anúncios e identifica-se um total de 236 competências com designações diferentes, mas outras com conjugações diferentes de uma mesma competência (e.g. comunicação ou capacidade de comunicação). Por isso, num primeiro momento, desenvolveu-se uma análise de conteúdo para agregar competências similares de modo a obter um número mais reduzido e operacional. Desta análise, resultaram 23 competências que são apresentadas no quadro $4 \mathrm{e}$ agrupadas com base nas propostas de classificação sistematizadas no quadro 1.

A terceira coluna do quadro mostra a frequência relativa com que as competências foram referidas nos anúncios. É de salientar a relevância das línguas estrangeiras, que surgem em cerca de $78 \%$ dos anúncios, dos quais $56,6 \%$ se referem ao inglês, enquanto $10,2 \%$ exigem o espanhol, $6,9 \%$ o francês e 3,2\% o alemão.

Os empregadores procuram também candidatos com capacidade de planear e organizar (52\%) e com capacidades de comunicação e trabalho em equipa. 
Certas competências surgem com menos frequência, como por exemplo, o espírito crítico $(8,7 \%)$, a negociação $(7,5 \%)$, a orientação para o cliente $(6,8 \%)$ e a apresentação $(3,5 \%)$.

\section{Análise estatística multivariada e de associação}

O tratamento de dados visa identificar tipos de competências e a associação entre esses tipos e outros atributos exigidos aos graduados. Para tal, a análise empírica suporta-se em três técnicas de estatística multivariada, designadamente: análise de correspondências múltiplas (ACM); análise de clusters hierárquica; e análise de clusters não hierárquica, com recurso ao método K-médias.

A ACM permite identificar a estrutura de dados existente e a relação entre um conjunto de variáveis qualitativas (Asselin e Anh, 2008; Di Franco, 2016; Huong, Hamid e Aziz, 2015), possibilitando a criação de um número reduzido de variáveis quantitativas compósitas, designadas dimensões. Adicionalmente foi aplicado um método de agrupamento - análise de clusters - com o objetivo de distribuir os anúncios em tipos ou grupos, de acordo com os perfis de competências requeridas, anteriormente representados no plano da ACM (Carvalho, 2017). Inicialmente aplicou-se uma análise de clusters hierárquica, com recurso ao método de agregação de Ward, com o objetivo de confirmar o número de grupos de anúncios, em função dos perfis apresentados no plano da ACM. Em seguida, os anúncios foram agrupados através da aplicação de uma análise de clusters não hierárquica, com recurso ao método K-médias, utilizando as dimensões quantitativas geradas com a ACM, como variáveis de segmentação.

Na etapa seguinte, a análise empírica visa a análise da associação entre os tipos de competências e as outras características detalhadas nos anúncios. Para tal, utilizamos $V$ de Cramer, uma medida estatística que permite avaliar a associação entre duas variáveis qualitativas nominais. Os resultados desta análise permitem perceber que características individuais, do emprego e do empregador estão relacionadas com cada perfil de competências.

\section{Análise empírica}

\section{Perfis de competências}

A primeira aplicação da análise de correspondências múltiplas (ACM) permite observar que existem quatro competências que não discriminam os anúncios, ou seja, que não são importantes na formação das dimensões estruturantes dos perfis de anúncios. Assim, as competências de apresentação, criatividade, orientação para o cliente e negociação foram retiradas da análise. Verifica-se também que se trata de competências pouco frequentes nos anúncios.

Por outro lado, pode sugerir-se que a língua estrangeira representa a competência-chave que os graduados devem dominar para trabalhar em Portugal e apoiar a estratégia de internacionalização das empresas. Esta surge na maioria dos 


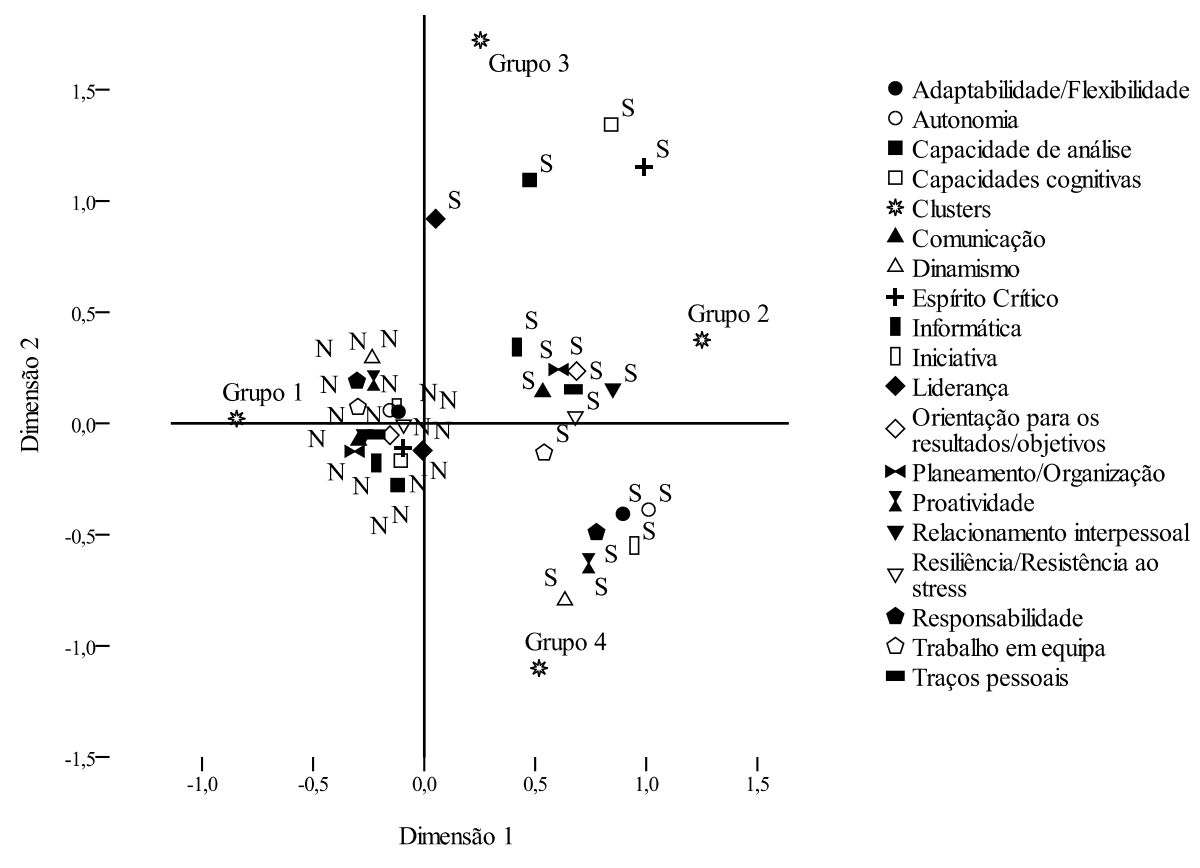

Figura 1 Distribuição espacial das competências procuradas nos anúncios

anúncios e por este facto também não tem poder discriminante. É assim igualmente excluída da análise.

A aplicação da ACM às 18 competências restantes conduz a duas dimensões quantitativas. A primeira dimensão opõe a ausência à presença das competências nos anúncios e a segunda dimensão separa diferentes competências requeridas. A distribuição espacial da presença/ausência de competências nos anúncios sugere a formação de quatro perfis (figura 1).

A análise de clusters hierárquica permite validar a existência de quatro perfis de competências que emergiram da ACM. Em seguida, aplicou-se uma análise de clusters não hierárquica, através de um método de otimização de K-médias, para agrupar os anúncios nos quatro grupos previstos. O quadro 5 apresenta a caracterização dos quatro grupos de anúncios encontrados, em função das competências requeridas. Um primeiro olhar sobre os resultados empíricos aponta para uma dicotomia entre anúncios que especificam as competências (grupos 2,3 e 4 ) e aqueles em que os requisitos em termos de conhecimentos e capacidades procuradas não são detalhados.

Os resultados apresentados no quadro 5 indicam que 43,9\% dos anúncios de emprego omitem informação sobre as competências requeridas. Por outro lado, os resultados sugerem três tipos de competências procuradas, que designamos capacidades relacionais e organizacionais, capacidades gerais e cognitivas, e traços pessoais. 
Quadro 5 Classificação dos tipos de competências procurados nos anúncios

\begin{tabular}{lll}
\hline Grupos & Competências & \% Presença \\
\hline $\begin{array}{l}\text { Grupo } 1 \\
\text { Sem especificação } \\
\left(\mathrm{n}_{1}=357 ; 43,9 \%\right)\end{array}$ & $\begin{array}{l}\text { Grupo de anúncios onde as competências } \\
\text { raramente se solicitam }\end{array}$ & \\
\hline & & 64,8 \\
Grupo 2 & Comunicação & 59,4 \\
Capacidades relacionais & Trabalho em equipa & 58,6 \\
e organizacionais & Planeamento/organização & 56,3 \\
$\left(\mathrm{n}_{2}=128 ; 15,7 \%\right)$ & Informática & 53,9 \\
& Relacionamento interpessoal & 50,8 \\
& Atitudes face ao trabalho & 50,0 \\
\hline Grupo 3 & Responsabilidade & 68,5 \\
Capacidades gerais e cognitivas & Capacidade de análise & 56,5 \\
$\left(\mathrm{n}_{3}=108 ; 13,3 \%\right)$ & Planeamento/organização & 55,6 \\
\hline Grupo 4 & Informática & 65,0 \\
Traços pessoais & Dinamismo & 55,9 \\
$\left(\mathrm{n}_{4}=220 ; 27,1 \%\right)$ & Responsabilidade & 55,5 \\
\hline
\end{tabular}

As capacidades relacionais e organizacionais dizem respeito à interação entre indivíduos internos e externos à organização, individualmente ou em grupo. Trata-se de capacidades de comunicação, trabalho em equipa, relacionamento interpessoal e atitudes face ao trabalho, como se pode aferir a partir dos dados apresentados no quadro 4 . As designadas capacidades gerais e cognitivas agregam a capacidade de análise, de planear e organizar, mas igualmente conhecimentos de informática. Finalmente, os traços pessoais incluem dinamismo, responsabilidade e proatividade.

As designações atribuídas inspiram-se na literatura analisada anteriormente e prendem-se com a prevalência de certas capacidades no agrupamento. Sublinhamos, contudo, que a classificação obtida a partir da estatística multivariada tende a agregar diferentes tipos de competências e, por isso, existem capacidades que não se encaixam perfeitamente nas designações adotadas. Por exemplo, a informática e o planeamento não são capacidades relacionais, mas no grupo 2 prevalecem a comunicação, o trabalho em equipa e o relacionamento interpessoal que nos levam a designá-lo dessa forma. Além disso, há capacidades que são transversais a mais de um agrupamento, o que dificulta a classificação clara das competências. Acrescentamos ainda a classificação de traços pessoais que decorre da literatura que enuncia apenas dois tipos de competências (Branine, 2008).

A análise subsequente incide sobre outros atributos especificados nos anúncios, bem como as componentes da relação de emprego divulgadas pelo empregador. Uma primeira abordagem trata a qualificação académica e sua associação aos tipos de competências procuradas, que, apesar de muito fraca, é estatisticamente significativa ( $V$ de Cramer $=0,2$ ).

Os resultados apresentados no quadro 6 indicam que as áreas de formação de engenharia e saúde surgem maioritariamente associadas a anúncios onde não são especificadas as competências ( $53,8 \%$ e $59,7 \%$, respetivamente). Todavia, quando 
Quadro 6 Tipos de competências e áreas de formação

\begin{tabular}{|c|c|c|c|c|c|c|c|c|c|c|}
\hline \multirow{4}{*}{ Áreas de formação } & \multicolumn{8}{|c|}{ Grupos } & \multirow{3}{*}{\multicolumn{2}{|c|}{ Total }} \\
\hline & \multirow{2}{*}{\multicolumn{2}{|c|}{$\begin{array}{c}\text { Grupo } 1 \\
\text { Sem } \\
\text { especificação }\end{array}$}} & \multirow{2}{*}{\multicolumn{2}{|c|}{$\begin{array}{c}\text { Grupo } 2 \\
\text { Capacidades } \\
\text { relacionais } \\
\text { e organizacionais }\end{array}$}} & \multirow{2}{*}{\multicolumn{2}{|c|}{$\begin{array}{c}\text { Grupo } 3 \\
\begin{array}{c}\text { Capacidades } \\
\text { gerais } \\
\text { e cognitivas }\end{array}\end{array}$}} & \multirow{2}{*}{\multicolumn{2}{|c|}{$\begin{array}{c}\text { Grupo } 4 \\
\text { Traços } \\
\text { pessoais }\end{array}$}} & & \\
\hline & & & & & & & & & & \\
\hline & $\mathrm{n}$ & $\%$ & $\mathrm{n}$ & $\%$ & $\mathrm{n}$ & $\%$ & $\mathrm{n}$ & $\%$ & $\mathrm{n}$ & $\%$ \\
\hline Engenharia & 206 & 53,8 & 46 & 12,0 & 41 & 10,7 & 90 & 23,5 & 383 & 100 \\
\hline Saúde & 40 & 59,7 & 3 & 4,5 & 8 & 11,9 & 16 & 23,9 & 67 & 100 \\
\hline Gestão & 70 & 27,2 & 64 & 24,9 & 49 & 19,1 & 74 & 28,8 & 257 & 100 \\
\hline Arquitetura e design & 9 & 31,0 & 3 & 10,3 & 1 & 3,4 & 16 & 55,2 & 29 & 100 \\
\hline Ciências sociais & 20 & 42,6 & 10 & 21,3 & 1 & 2,1 & 16 & 34,0 & 47 & 100 \\
\hline Outras & 12 & 40,0 & 2 & 6,7 & 8 & 26,7 & 8 & 26,7 & 30 & 100 \\
\hline
\end{tabular}

Quadro 7 Tipos de competências e funções a ocupar

\begin{tabular}{|c|c|c|c|c|c|c|c|c|c|c|}
\hline \multirow{4}{*}{ Função a ocupar } & \multicolumn{8}{|c|}{ Grupos } & \multirow{3}{*}{\multicolumn{2}{|c|}{ Total }} \\
\hline & \multirow{2}{*}{\multicolumn{2}{|c|}{$\begin{array}{c}\text { Grupo } 1 \\
\text { Sem } \\
\text { especificação }\end{array}$}} & \multirow{2}{*}{\multicolumn{2}{|c|}{$\begin{array}{c}\text { Grupo } 2 \\
\text { Capacidades } \\
\text { relacionais e } \\
\text { organizacionais }\end{array}$}} & \multirow{2}{*}{\multicolumn{2}{|c|}{$\begin{array}{c}\text { Grupo } 3 \\
\text { Capacidades } \\
\text { gerais e } \\
\text { cognitivas }\end{array}$}} & \multirow{2}{*}{\multicolumn{2}{|c|}{$\begin{array}{c}\text { Grupo } 4 \\
\text { Traços } \\
\text { pessoais }\end{array}$}} & & \\
\hline & & & & & & & & & & \\
\hline & $n$ & $\%$ & $\mathrm{n}$ & $\%$ & $\mathrm{n}$ & $\%$ & $\mathrm{n}$ & $\%$ & $\mathrm{n}$ & $\%$ \\
\hline Assistente & 18 & 34,6 & 8 & 15,4 & 11 & 21,2 & 15 & 28,8 & 52 & 100 \\
\hline Técnico & 140 & 41,5 & 62 & 18,4 & 39 & 11,6 & 96 & 28,5 & 337 & 100 \\
\hline Quadro superior & 148 & 51,0 & 36 & 12,4 & 34 & 11,7 & 72 & 24,8 & 290 & 100 \\
\hline Gestor & 46 & 37,1 & 21 & 16,9 & 22 & 17,7 & 35 & 28,2 & 124 & 100 \\
\hline
\end{tabular}

surgem competências especificadas, estas referem-se a traços pessoais (23,5\% e $23,9 \%$, respetivamente).

A área da gestão surge maioritariamente associada a alguma especificação de competências, sejam ligadas a traços pessoais $(28,8 \%)$, a capacidades relacionais e organizacionais $(24,9 \%)$ ou a capacidades gerais e cognitivas $(19,1 \%)$. Os anúncios para a área de ciências sociais mencionam traços pessoais (34\%) e capacidades relacionais e organizacionais $(21,3 \%)$. Contudo, existe um número elevado de anúncios onde não se especificam competências (42,6\%). Finalmente, a maioria da procura de profissionais de arquitetura e design surge associada a anúncios onde são mencionadas competências ligadas a traços pessoais (55,2\%).

A associação entre os tipos de competências procuradas e a função a ocupar, apesar de não apresentar significância estatística $(V$ de Cramer $=0,08)$ oferece também particularidades interessantes (quadro 7). Neste sentido, verificamos que 
todas as funções surgem com maior frequência em anúncios onde não são especificadas competências. Quando surgem em anúncios onde se mencionam competências, são os traços pessoais que com maior frequência os empregadores procuram nos seus profissionais, independentemente da função a exercer.

É ainda de sublinhar que, no caso dos quadros superiores, a maioria da procura não surge associada a especificação de competências (51\%), possivelmente associada ao facto de se mencionar a sua área de formação $(71 \%$ destes anúncios pedem licenciados em engenharia).

\section{Discussão dos resultados}

A evidência empírica obtida através da análise de anúncios de emprego suscita um conjunto de questões que importa discutir. Desde logo, é importante salientar que os anúncios são heterogéneos e, como tal, contêm informação diferenciada, sendo uns mais detalhados que outros. É ainda de notar que uma proporção relevante dos anúncios $(43,9 \%)$ não informa acerca das competências procuradas. Vimos que a especificação pode ser, nas palavras de Bennett (2002), útil para atrair candidatos mais ajustados e consequentemente desmobilizar aqueles que se sintam distantes de tais exigências. Poderemos então questionar o que motiva os empregadores a não especificar as competências requeridas. A resposta a esta questão pressupõe um olhar sobre as outras características procuradas.

Os resultados empíricos sugerem que se trata essencialmente de anúncios relacionados com áreas técnicas de formação, designadamente saúde e engenharia. Julgamos que os empregadores procuram candidatos com conhecimentos técnicos específicos, indicando a área de formação, no pressuposto de que a ausência dessa formação invalida o acesso aos empregos respetivos. Quer isto dizer que os empregadores procuram competências técnicas adquiridas pela formação universitária e necessitam de atrair candidatos com qualificação académica ajustada, relegando eventualmente a identificação de outras competências para posteriores fases de seleção. Os resultados sugerem ainda uma confiança dos empregadores na qualidade do ensino superior e na eventual preparação dos graduados para o mercado de trabalho, pelo menos nestas áreas. Este argumento contraria, em certa medida, as conclusões de outras pesquisas que apontam no sentido da insuficiente preparação dos graduados (Hesketh, 2000; Bennett, 2002; Kavanagh e Drennan, 2008). Estas questões abrem espaço para pesquisas futuras no sentido de analisar a perceção dos empregadores sobre as competências adquiridas por graduados de diferentes áreas de formação.

Em suma, a oferta de emprego para estas áreas parece sinalizar aos candidatos a relevância dos conhecimentos técnicos adquiridos através da formação superior. Em contrapartida, as ofertas para as áreas de ciências sociais e de gestão tendem a ser mais detalhadas e incidem especialmente em traços pessoais e capacidades relacionais e organizacionais. Podemos pois concluir que existe uma diferença entre anúncios dirigidos ao recrutamento de graduados em ciências técnicas (engenharia e saúde) e ciências sociais. 
A discussão seguinte visa as competências mais frequentemente procuradas e explicitadas nos anúncios de emprego. Sugerimos que a língua estrangeira configura uma competência-chave (Barth et al., 2007) ou essencial (Bennett, Dunne e Carré, 1999) no mercado de trabalho português, especialmente o inglês, que é referido em $56,6 \%$ dos anúncios com referência a língua estrangeira, tal como acontece noutros mercados (e.g. Chancelade et al., 2015, para a França). Contudo, é importante sublinhar que outras línguas estrangeiras são relevantes, designadamente o espanhol. Esta procura parece sugerir que as empresas em Portugal visam uma diversidade de mercados internacionais e, como tal, necessitam de indivíduos com domínio de línguas ajustado a esses mercados. As universidades precisam pois de responder a essa procura e preparar os futuros graduados para um mercado globalizado.

Uma outra discussão prende-se com a classificação das competências. A literatura é pouco consensual e as múltiplas propostas deixavam antever alguma dificuldade. De facto, a análise estatística multivariada oferece uma agregação em que se sobrepõem diferentes tipos de competências. Por exemplo, o grupo 2, capacidades relacionais e organizacionais (quadro 5), junta competências que os estudos empíricos analisados tendem a separar. Todavia, devemos sublinhar que parece existir uma certa coerência nesse grupo. Ou seja, as empresas procuram graduados que consigam interagir, planear e organizar, sejam responsáveis no e para com o trabalho, e tenham conhecimentos de ferramentas informáticas, que no conjunto são competências gerais (H1). Mais do que a classificação, importa reter este "pacote" de competências que as empresas procuram. O mesmo raciocínio prevalece para os outros agrupamentos. Por exemplo, certas empresas sublinham a importância de traços pessoais (grupo 4), enquanto outras preferem atrair candidatos com capacidades gerais e cognitivas (grupo 3). Estes resultados corroboram a nossa hipótese de que os empregadores privilegiam os traços pessoais (H2). Branine (2008) reconheceu essa exigência e os nossos resultados vão no mesmo sentido, uma vez que os traços pessoais são detalhados em $27,1 \%$ dos anúncios.

A informação sobre a procura de competências por áreas de formação sugere alguma heterogeneidade. Certos anúncios para a área de engenharia fazem referência a competências, indicando que os empregadores procuram candidatos com traços pessoais e capacidades relacionais e organizacionais. Estes resultados não diferem assim daqueles previstos para a profissão de engenheiro, em que a pesquisa empírica sublinha a relevância da capacidade de comunicação (Sageev e Romanowski, 2001; Riemer, 2007), que representa a competência mais frequente do grupo 2. Em contrapartida, os anúncios para a área de gestão seguem um padrão distinto. Os empregadores sinalizam aos potenciais candidatos as suas preferências por todos os tipos de competências. É importante notar que a pesquisa disponível sobre a procura de competências é especialmente relevante na área de gestão (e.g. Boyatzis, 1982; Bennett, 2002; Kumar e Jain, 2010; Velasco, 2012) e especialidades dentro da gestão (e.g. Almeida, 2000; Kavanagh e Drennan, 2008; Torres, 2008). Quer isto dizer que traços pessoais prevalecem como critérios de recrutamento em certas áreas de formação (H3).

Todavia, os nossos resultados não são particularmente conclusivos sobre a associação entre competências e funções a desempenhar. Como se pode verificar a partir 
da evidência empírica reportada no quadro 7 , os traços pessoais são exigidos em todas as funções. Assim sendo, a nossa hipótese 3 fica apenas parcialmente validada.

Em suma, os exemplos analisados reforçam o debate sobre a necessidade de as universidades preparem graduados para o mercado de trabalho, desenvolvendo especialmente competências que as empresas procuram. Nesse conjunto sobressaem as capacidades de planear e organizar, comunicação, e trabalho em equipa que, em conjunto com a língua estrangeira, representam as competências-chave para o mercado de trabalho português. Estas são classificadas de diferente forma na literatura analisada, especialmente a comunicação, que é uma capacidade relacional (Suleman, 2012) e geral (Garcia-Aracil e van der Velden, 2008), a qual é basilar (Olivier et al., 2014) e instrumental (Teijeiro, Rungo e Freire, 2013). Além disso, é transversal a muitas profissões. Se, por um lado, esta informação é relevante para o ensino superior, por outro lado, revela que existe um fraco consenso sobre as competências requeridas. Eventualmente, os empregadores tendem a reportar atributos mais facilmente observáveis (Suleman, 2017).

\section{Conclusão}

Esta pesquisa procurou explorar anúncios de emprego para identificar competências procuradas no mercado de trabalho português. Um contributo essencial que sobressai da análise empírica remete para a identificação de competências-chave (Barth et al., 2007) ou competências essenciais (Bennett, Dunne e Carré, 1999), designadamente a língua estrangeira, e o inglês em particular. No que respeita a outras competências, os resultados apontam no mesmo sentido que outras pesquisas internacionais. No mercado de trabalho nacional atribui-se importância às competências relacionais, com destaque para a capacidade de comunicação. Os empregadores exigem igualmente traços pessoais, como dinamismo, responsabilidade e proatividade. Todavia, as exigências variam de acordo com as áreas de formação. Estes resultados indicam que os anúncios de emprego tendem a enumerar poucas competências, as quais veiculam particularmente informação sobre o "pacote" que os empregadores valorizam.

Apesar do contributo desta pesquisa para a análise do recrutamento, os resultados obtidos merecem ser analisados com cautela. A análise de anúncios não se apoia em listas de competências, o que obriga o investigador a interpretar e agregar a multiplicidade de capacidades requeridas pelos empregadores. Contudo, este exercício é necessário para informar o ensino superior - uma vez que as empresas tendem a iniciar os seus processos de recrutamento através de anúncios de emprego e formar uma base de recrutamento de futuros empregados (Gorter, Nijkamp e Rietveld, 1996). Além disso, é importante ter em atenção o enviesamento na recolha de informação. Embora os sítios da internet sejam amplamente preferidos (Lanier, 2009), certas empresas podem optar por outros meios de divulgação de ofertas de emprego. Em pesquisas futuras é necessário analisar se existe alguma associação entre as funções a ocupar e a opção por um meio de divulgação de ofertas.

Uma outra limitação importante deste estudo prende-se com a diversidade das competências enunciadas. Em estudos futuros, seria interessante construir um 
referencial a partir dos anúncios e utilizá-lo para recolher informação sobre as competências requeridas junto dos empregadores.

Apesar das limitações desta pesquisa, as universidades em Portugal podem beneficiar deste tipo de estudos para conhecer as tendências do mercado de trabalho e equacionar a formação em competências requeridas. Um claro exemplo prende-se com as línguas estrangeiras, cuja formação implica meios formais, como lecionação de aulas e incentivo à leitura de textos, e informais, através do intercâmbio com estudantes de diferentes origens.

\section{Referências bibliográficas}

Almeida, António José (2000), “Perfis de competências dos profissionais da gestão de Recursos Humanos: da ilusão estratégica à estratégia da desilusão", Recursos Humanos Magazine, nov./dez, pp. 10-22.

Andrews, Jane, e Helen Higson (2008), “Graduate employability, 'soft skills' versus 'hard' business knowledge: a European study", Higher Education in Europe, 33 (4), pp. 411-422.

Arcodia, Charles, e Tanuja Barker (2002), "A review of web-based job advertisements for Australian event management positions", Journal of Human Resources in Hospitality $\mathcal{E}$ Tourism, 1 (4), pp. 1-18.

Arrow, Kenneth Joseph (1973), "Higher education as a filter", Journal of Public Economics, 2, pp. 193-216.

Asselin, Louis-Marie, e Vu Tuan Anh (2008), “Multidimensional poverty and multiple correspondence analysis", em Nanak Kakwani e Jacques Silber, Quantitative Approaches to Multidimensional Poverty Measurement, Palgrave Macmillan UK, pp. 80-103.

Barth, Matthias, Jasmin Godemann, Marco Rieckmann, e Ute Stoltenberg (2007), "Developing key competencies for sustainable development in higher education", International Journal of Sustainability in Higher Education, 8 (4), pp. 416-430.

Becker, Gary S. (1964), Human Capital. A Theoretical and Empirical Analysis, with Special Reference to Education, Nova Iorque, Columbia University Press.

Bennett, Neville, Elisabeth Dunne, e Clive Carré (1999), “Patterns of core and generic skill provision in higher education", Higher Education, 37, pp. 71-93.

Bennett, Roger (2002), “Employers' demands for personal transferable skills in graduates: a content analysis of 1000 job advertisements and an associated empirical study", Journal of Vocational Education E Training, 54 (4), pp. 457-476.

Billing, D. (2003), “Generic cognitive abilities in higher education: an international analysis of skills sought by stakeholders", Compare, 33 (3), pp. 335-350.

Boyatzis, Richard E. (1982), The Competent Manager. A Model for Effective Performance, Nova Iorque, John Wiley \& Sons, pp. 10-39.

Branine, Mohamed (2008), "Graduate recruitment and selection in the UK: a study of the recent changes in methods and expectations", Career Development International, 13 (6), pp. 497-513.

Cardoso, José Luís, Marta Pedro Varanda, Paulo Madruga, Vítor Escária, e Vítor Sérgio Ferreira (2012), Empregabilidade e Ensino Superior em Portugal - Relatório Final, Lisboa, Instituto de Ciências Sociais da Universidade de Lisboa (ICS-UL). 
Carvalho, Helena (2017), Análise Multivariada de Dados Qualitativos - Utilização da ACM com o SPSS, Lisboa, Edições Sílabo (2. a edição).

Chancelade, Carine, Patricia Janissin, Jean-François Giret, Christine Guégnard, Pernelle Benoit, e Amandine Vogt (2015), Analyse des Besoins des Employeurs Français au Regard des Compétences en Langues Etrangères, Marselha, Céreq.

Choi, Youngok, e Edie Rasmussen (2009), "What qualifications and skills are important for digital librarian positions in academic libraries? A job advertisement analysis", The Journal of Academic Librarianship, 35 (5), pp. 457-467.

Di Franco, Giovanni (2016), “Multiple correspondence analysis: one only or several techniques?", Quality \& Quantity, 50 (3), pp. 1299-1315.

Ellis, Simon P. (2003), "Anticipating employers' skills needs: the case for intervention", International Journal of Manpower, 24 (1), pp. 83-96.

Figueiredo, Hugo, Pedro Teixeira, e Jill Rubery (2013), “Unequal futures? Mass higher education and graduates' relative earnings in Portugal, 1995-2009", Applied Economics Letters, 20 (10), pp. 991-997.

García-Aracil, Adela, e Rolf van der Velden (2008), “Competencies for young European higher education graduates: labor market mismatches and their payoffs", Higher Education, 55 (2), pp. 219-239.

Gonçalves, Carlos Manuel (2017), "Diplomados universitários e sobre-educação", Sociologia: Revista da Faculdade de Letras da Universidade do Porto, número temático — "Processos sociais e questões sociológicas", pp. 42-74.

Gorter, Cees, Peter Nijkamp, e Piet Rietveld (1996), “Employers' recruitment behaviour and vacancy duration: an empirical analysis for the Dutch labour market", Applied Economics, 28 (11), pp. 1463-1474.

Harvey, Lee (2001), "Defining and measuring employability", Quality in Higher Education, 7 (2), pp. 97-109.

Henricks, Susan A., e Genevieve Henricks-Lepp (2014), “Desired characteristics of management and leadership for public library directors as expressed in job advertisements", Journal of Library Administration, 54 (4), pp. 277-290.

Hesketh, Anthony J. (2000), “Recruiting an elite? Employers' perceptions of graduate education and training", Journal of Education and Work, 13, pp. 245-271.

Hillage, Jim, e Emma Pollard (1998), “Employability: developing a framework for policy analysis", Research Brief, 85, Londres, Department for Education and Employment.

Huong, Penny Ngu Ai, Hashibah binti Hamid, e Nazrina binti Aziz (2015), “Multiple correspondence analysis for handling large binary variables in smoothed location model", em AIP Conference Proceedings, Innovation and Analytics Conference and Exhibition, IACE 2015: Proceedings of the $2^{\text {nd }}$ Innovation and Analytics Conference $\mathcal{E}$ Exhibition, 1691 (1), Nova Iorque, AIP Publishing.

Kavanagh, Marie H., e Lyndal Drennan (2008), “What skills and attributes does an accounting graduate need? Evidence from student perceptions and employer expectations", Accounting and Finance, 48 (2), pp. 279-300.

Kennan, Mary Anne, Patricia Willard, Dubravka Cecez-Kecmanovic, Concepción S. Wilson (2009), "Is knowledge and skills sought by employers: a content analysis of Australian is early career online job advertisements", Australasian Journal of Information Systems, 15 (2), pp. 169-190. 
Kumar, Dileep, e Vishal Jain (2010), “Survival skills of business management graduates: a study with reference to retail and banking", Far East Journal of Psychology and Business, 1 (1), pp. 49-77.

Lanier, Clinton R. (2009), "Analysis of the skills called for by technical communication employers in recruitment postings", Technical Communication, 56 (1), pp. 51-61.

Maguire, Peter, e Carolyn Pitceathly (2002), “Key communication skills and how to acquire them", British Medical Journal, 325, pp. 697-700.

Mavromaras, Kostas, Seamus McGuinness, Nigel O'Leary, Peter Sloane, e Zhang Wei (2013), "Job mismatches and labour market outcomes: panel evidence on university graduates", Economic Record, 89 (286), pp. 382-395.

McQuaid, Ronald W., e Colin Lindsay (2005), “The concept of employability”, Urban Studies, 42 (2), pp. 197-219.

Messum, Diana, Lesley Wilkes, e Debra Jackson (2011), “Employability skills: essential requirements in health manager vacancy advertisements", Asia Pacific Journal of Health Management, 6 (2), pp. 22-28.

Morand, David A. (2001), “The emotional intelligence of managers: assessing the construct validity of a nonverbal measure of 'people skills'", Journal of Business and Psychology, 16 (1), pp. 21-33.

Olivier, Damian, Brigid Freeman, Craig Young, Serena Yu, e Garima Verma (2014), Employer Satisfaction Survey, Sydney, The University of Sydney Business School, Report for the Department of Education.

Pitt, Rachael, e Inger Mewburn (2016), "Academic superheroes? A critical analysis of academic job descriptions", Journal of Higher Education Policy and Management, 38 (1), pp. 88-101.

Riemer, Marc J. (2007), “Communication skills for the $21^{\text {st }}$ century engineer”, Global Journal of Engineering Education, 11 (1), pp. 89-98.

Sageev, Pneena, e Carol J. Romanowski (2001), “A message from recent engineering graduates in the workplace: results of a survey on technical communication skills", Journal of Engineering Education, 90 (4), pp. 685-693.

Suleman, Fátima (2012), “The impact of skills and performance on earnings: the evidence from retail bankers", International Journal of Human Resource Management, 23 (11), pp. 2205-2220.

Suleman, Fátima (2017), “The employability skills of higher education graduates: insights into conceptual frameworks and methodological options", Higher Education, DOI: 10.1007/s10734-017-0207-0.

Suleman, Abdul, e Fátima Suleman (2012), “Ranking by competence using a fuzzy approach", Quality \& Quantity, 46 (1), pp. 323-339.

Teijeiro, Mercedes, Paolo Rungo, e M. Jesús Freire (2013), “Graduate competencies and employability: the impact of matching firms' needs and personal attainments", Economics of Education Review, 34, pp. 286-295.

Torres, Leonor Lima (2008), “Educação e trabalho: dinâmica da relação entre perfis de formação e perfis profissionais no campo dos recursos humanos", VI Congresso Português de Sociologia, junho, série 277.

Tymon, Alex (2013), "The student perspective on employability", Studies in Higher Education, 38 (6), pp. 841-856. 
Vazirani, Nitin (2010), “Competencies and competency model: a brief overview of its development and application", SIES Journal of Management, 7 (1), pp. 121-131.

Velasco, Manuel Salas (2012), “More than just good grades: candidates' perceptions about the skills and attributes employers seek in new graduates", Journal of Business Economics and Management, 13 (3), pp. 499-517.

Velden, Rolf van der (2013), "Measuring competencies in higher education", em S. Blömeke, O. Zlatkin-Troitschanskaia, C. Kuhn, e J. Fege (orgs.), Modeling and Measuring Competencies in Higher Education. Tasks and Challenges, Roterdão, Sense Publishers, pp. 207-216.

Washer, Peter (2007), "Revisiting key skills: a practical framework for higher education", Quality in Higher Education, 13 (1), pp. 57-67.

\section{Agradecimentos}

Agradecemos aos participantes da 2. ${ }^{\text {a }}$ edição do Workshop Interno do Dinâmia'Cet_Iscte “Dinâmicas Socioeconómicas e Territoriais Contemporâneas", 24 e 27 junho de 2016, e do IX Congresso Português de Sociologia, “Portugal Território de Territórios", Universidade do Algarve, de 6 a 8 de julho de 2016, e pelos comentários e sugestões à versão provisória desta pesquisa.

Ana Costa Laranjeiro. Doutoranda do Programa de Doutoramento em Gestão, especialização em Recursos Humanos e Comportamento Organizacional, formadora desde 1996, principalmente na área financeira e cursos profissionais, professora de Economia do ensino secundário.

E-mail: anancostalar@gmail.com

Fátima Suleman. Professora auxiliar, com agregação do Departamento de Economia Política, diretora do Departamento de Economia Política e investigadora do Dinâmia'Cet_Iscte, onde coordena a área de investigação de Trabalho.

E-mail: Fatima.Suleman@iscte-iul.pt

Maria do Carmo Botelho. Professora auxiliar do Departamento de Métodos de Pesquisa Social, investigadora do Cies_Iscte e coordenadora da pós-graduação em Visualização de Informação. E-mail: maria.botelho@iscte.pt

Receção: 16 de maio de 2018 Aprovação: 26 de junho de 2018 